\title{
Uniaxial compressive strength of geopolymer cement for oil well cement
}

\author{
Raja Rajeswary Suppiah ${ }^{1}$ (I) Siti Humairah A. Rahman ${ }^{2} \cdot$ Nasir Shafiq $^{1} \cdot$ Sonny Irawan ${ }^{1}$
}

Received: 1 November 2018 / Accepted: 28 May 2019 / Published online: 4 June 2019

(c) The Author(s) 2019

\begin{abstract}
Ensuring oil-well-integrity is one of the challenging tasks when cementing is designed. It has been well established that cement tends to degrade when exposed to a corrosive environment and at elevated temperatures. This paper presents the results of the uniaxial compressive strength of the qualified mixes of geopolymer cement containing fly ash as the precursor. Geopolymer cement samples were cured in the potable water heated at $60{ }^{\circ} \mathrm{C}$ and $90{ }^{\circ} \mathrm{C}$ for $24 \mathrm{~h}$ before testing for uniaxial compressive strength. Uniaxial confined compressive strength test was performed for samples cured at a $60{ }^{\circ} \mathrm{C}$, and results of the samples bearing density of 13,15 , and $17 \mathrm{ppg}$ were obtained as 4.12, 9.21 and $17.68 \mathrm{kPa}$, respectively. For $90{ }^{\circ} \mathrm{C}$, the compressive strengths were $4.43,15.34$ and $78.14 \mathrm{kPa}$, respectively, for the samples bearing the same density. Samples cured at $90{ }^{\circ} \mathrm{C}$ showed the higher value of UCS as compared to the samples cured at $60{ }^{\circ} \mathrm{C}$, and it was because heat is required to stimulate the polymeric reaction.
\end{abstract}

Keywords Ordinary Portland cement · Fly ash · Geopolymer cement · Uniaxial compressive strength · Oil well cement

\section{Introduction}

During a cementing job, cement transforms a liquid slurry being pumped down the wellbore to a solid material filling up the annular space between the casing and the borehole. While in the slurry state, the cement is characterized by rheological properties such as yield stress and plastic viscosity. When hardened, cement is characterized by properties that determine how stable and permeable it is, how well it binds to the casing and the rock or how prone it is to fracture. The most prevalent explanation for the stabilization of water in crude oil emulsions is the formation of

Raja Rajeswary Suppiah

rajarajeswary@utp.edu.my

Siti Humairah A. Rahman

humairah.rahman@ petronas.com.my

Nasir Shafiq

nasirshafiq@utp.edu.my

Sonny Irawan

drsonny_irawan@utp.edu.my

1 Department of Petroleum Engineering, UniversitiTeknologi PETRONAS, Seri Iskandar, Malaysia

2 PETRONAS Research Sdn Bhd, Bangi, Malaysia a rigid film at the interface between the two phases. This originates from the early observation of interface crumpling/ wrinkling upon contraction of water droplets aged in crude oils (Liu et al. 2017). These properties need to be controlled to obtain a robust low-permeability cement sheath in the well. Therefore, we start our journey into the world of well cementing by exploring some important cement properties. Proper slurry design is critical to the success of a cementing job. The best method to obtain a good slurry design with desired compressive strength is by laboratory experiments which involve experimenting different formulations and selecting the best composition for the specific cementing operation (Falode et al. 2013). Test experiments proved that fly ash-based geopolymer cement has excellent compressive strength and good acid resistance, which have been indicated at atmospheric pressure and temperature (Nasvi et al. 2012). Development of geopolymer as potential oil well cement is quite recent (Giasuddin et al. 2013). Geopolymer cement or alkali-activated cementitious materials are acid-resistant inorganic polymeric materials with zeolitic properties (Shi et al. 2011). Over the years, this geopolymer material has been investigated for many properties such as mechanical and rheological properties, compressive strength, thickening time, shrinkage, and it is acid resistivity at variable curing periods, temperatures and environments. Despite the fact

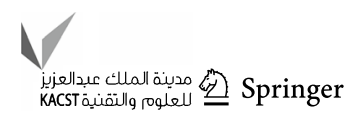


that a number of studies report data on viscosity of cement at different concentrations, temperatures, and pressures, until now, the effects of aging and cement aggregation have not been studied systematically (Mozaffari et al. 2015). Based on various studies, moderate to high compressive strength was yielded for geopolymer synthesis at high-temperature curing environment (Bakharev 2005; Kong and Sanjayan 2010; Kovalchuk et al. 2007).

Moreover, geopolymer is processed from waste materials which contribute to the added values of this raw material. Even though geopolymer cement has some advantages stacked up to OPC, it is stated that geopolymer cement only possesses better performance than Class $\mathrm{G}$ cement in terms of compressive strength at $36-80{ }^{\circ} \mathrm{C}$. However, it must be noted that there is a possibility of breaking up the intergranular structure of geopolymer at very high curing temperatures $\left(>100^{\circ} \mathrm{C}\right)$, and hence, it could lead to strength reduction.

The size, size distribution and stability of colloidal nanoparticles are greatly affected by the presence of capping ligands (Mozaffari et al. 2018). Cement hardening is due to hydration of cement which starts immediately or sometime after the cement slurry has been mixed. Hydration involves changes in both the structure and the properties of cement. In particular, the density of hydration products is higher than that of the original unhydrated phases. In the absence of extra water supply, this causes neat cement to shrink (Dusseault et al. 2007). As a result of chemical shrinkage, i.e., shrinkage due to hydration, porosity and pore pressure decrease as setting proceeds. It may also lead to the development of a microannulus between the cement and the formation, which is one of the mechanisms behind well leakage.

At the same time, cement experiences different types of stress scenarios once cured and placed in a subterranean environment. Therefore, the mechanical behavior of wellbore cement system is essential. Wellbore cement undergoes varying stress states upon reservoir re-pressurization and continuous expansion. It determines the inevitability to investigate mechanical strength of geopolymer cement under uniaxial compressive strength. Given very small yield stress, it was difficult to precisely distinguish between Newtonian and non-Newtonian Bingham Plastic behavior (Mozaffari et al. 2017).

\section{Materials}

The raw material used for the preparation of the geopolymer cement was ASTM Class 'F' fly ash used as aluminosilicate source material for synthesis of geopolymer cement. Sodium hydroxide $(\mathrm{NaOH})$ pellets with $98 \%$ purity ( $\&$ M Chemicals, Malaysia) were pre-prepared before usage. Pre-mixed $\mathrm{NaOH}$ and sodium silicate $\left(\mathrm{Na}_{2} \mathrm{SiO}_{3}\right)$ solution of the specific gravity of 1.53 (R\&M Chemicals, Malaysia) were mixed before the addition of solid particles. The YTL Cement, Malaysia, supplied class ' $F$ ' fly ash. The sodium hydroxide in pellets form and good quality sodium silicate were received from Avantis Laboratory Supply, Malaysia.

\section{Methods}

\section{Cement preparation}

The cement cylinders were prepared using geopolymerization process of mixing fly ash and alkaline activator at different ratios depending on the desired density. The materials were proportioned by weight. The mixing was carried out using a speed mixer operated at 4000 and 12,000 rpm for $50 \mathrm{~s}$. Cylindrical specimens were made of $1.5 \mathrm{in}$. diameter with 3 in. length. The molds filled with slurry were kept in a water bath at $60^{\circ} \mathrm{C}$ and $90{ }^{\circ} \mathrm{C}$ for $24 \mathrm{~h}$. During preparation of pastes, no problem was encountered in the stability of the paste as well there was not observed any phase separation in the paste.

\section{Cement curing}

After the molds were taken out from the water bath, the samples were carefully pushed out of the cylindrical molds. The samples were then sent for cutting according to the specified size. Cut samples were kept in a container filled with tap water before mechanical testing.

\section{Experimental setup}

Cylindrical samples were loaded axially in the testing machine between the loading platens with deformation measurement equipment attached on the specimen.

\section{Test analysis}

\section{Uniaxial compressive strength (UCS)}

The cured samples were tested for uniaxial compressive strength (UCS) using ASTM D 7012-04. This test method covers the determination of the strength of intact rock core specimens in uniaxial compression and confined compression. This test method covers the determination of the strength of intact rock core specimens in uniaxial compression and confined compression. The tests provide data in determining the strength of rock, namely the uniaxial strength, shear strengths at varying pressures and varying temperatures, angle of internal friction (angle of shearing resistance), and cohesion intercept. The test method specifies 


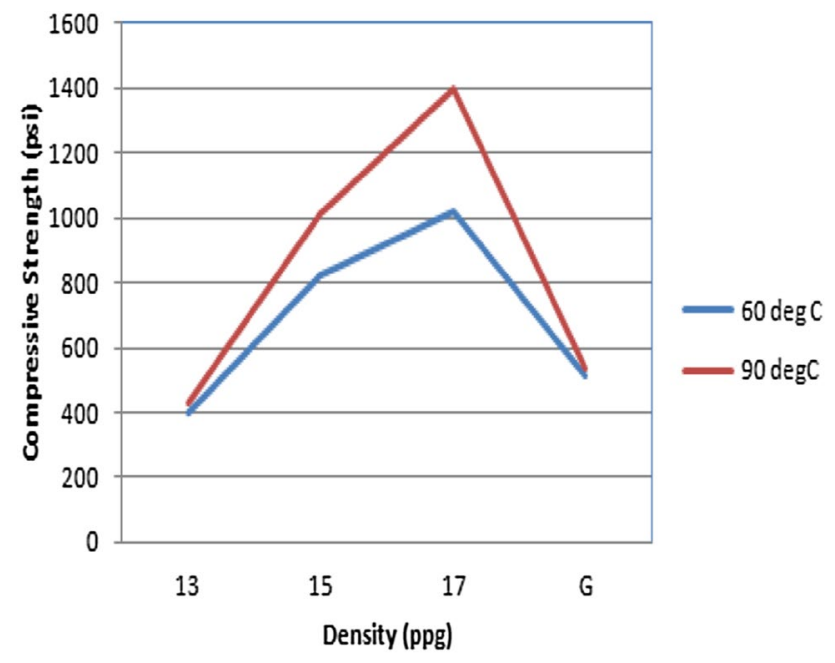

Fig. 1 Strength of geopolymer at 60 and $90{ }^{\circ} \mathrm{C}$

the apparatus, instrumentation, and procedures for determining the stress-axial strain and the stress-lateral strain curves, as well as Young's modulus, $E$, and Poisson's ratio. It should be observed that this method makes no provision for pore pressure measurements and specimens are undrained (platens are not vented). Thus, the strength values determined are in terms of total stress, that is, are not corrected for pore pressures. This test method does not include the procedures necessary to obtain a stress-strain curve beyond the ultimate strength. The tests provide data in determining the strength of rock, namely the uniaxial strength, shear strengths at varying pressures and varying temperatures, angle of internal friction (angle of shearing resistance), and cohesion intercept.

\section{Results and discussion}

\section{Uniaxial compressive strength (UCS)}

In order to examine the effect of temperature on strength development of geopolymer, samples were cured at $60{ }^{\circ} \mathrm{C}$ and $90^{\circ} \mathrm{C}$. All results of the uniaxial compressive strength (UCS) are shown in Fig. 1. There are three (3) groups of mixes based on the density of mixes of 13,15, 17 ppg and class $\mathrm{G}$ cured at $60{ }^{\circ} \mathrm{C}$ and $90{ }^{\circ} \mathrm{C}$. All cement samples followed the failure mechanism governed by axial splitting. At low to intermediate confining pressure, cement usually fails along conjugate or single shear planes. For each density, two samples were taken and tested, and the reported value indicates the average strength of the two samples $\left(\mathrm{A}: 60^{\circ} \mathrm{C}\right.$ and AA: $90{ }^{\circ} \mathrm{C}$ ). Results for each of the groups were very consistent, and a low coefficient of variation was observed.

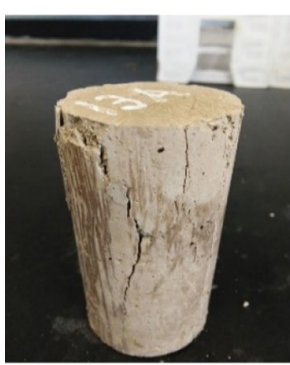

13A

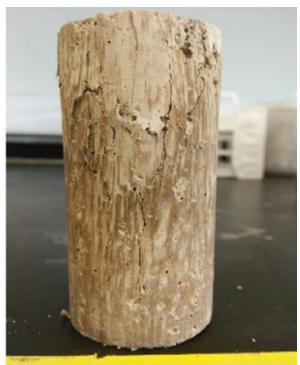

13AA
Fig. 2 Cement sample of 13 ppg after a compressive strength test at $60{ }^{\circ} \mathrm{C}$ and $90{ }^{\circ} \mathrm{C}$

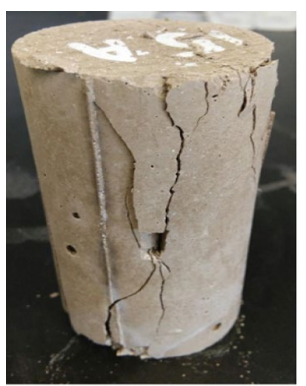

15A

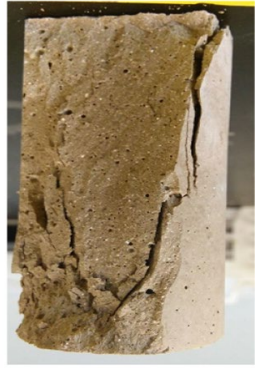

15AA
Fig. 3 Cement samples of 15 ppg after a compressive strength test $60{ }^{\circ} \mathrm{C}$ and $90{ }^{\circ} \mathrm{C}$

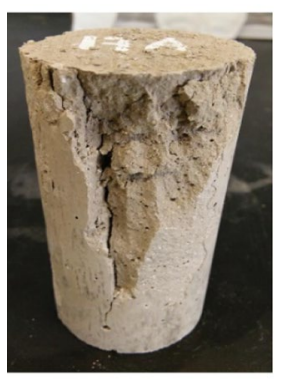

17A

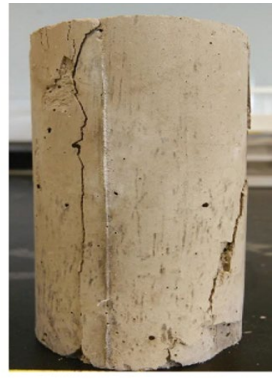

17AA
Fig. 4 Cement samples of 17 ppg after a compressive strength test $60{ }^{\circ} \mathrm{C}$ and $90{ }^{\circ} \mathrm{C}$

For each of the data point, an error of $\pm 3 \%$ was estimated, which considered acceptable (Figs. 2, 3, 4).

The pictures shown above were snapped at the time of failure. Such pictures are depicting the failure mode and behavior of samples. In all the samples, uniaxial (along with the length of cylindrical samples) cracks are observed. Almost every sample resisted the complete crushing, in few samples, few fragments disintegrated from the specimens. 
Geopolymer binders reacted upon receiving the heat or in other sense; these are endothermic in nature. This phenomenon is reflected in the compressive strength test results. The binder containing a density of $17 \mathrm{ppg}$ and cured at $90{ }^{\circ} \mathrm{C}$ showed the highest compressive strength as $1400 \mathrm{psi}$. Because the high temperature supplied more heat for a chemical reaction to take place and higher density caused the mix to be more compacted, the mix resulted in higher compressive strength. When geopolymers were cured at a higher temperature in civil engineering research, it showed that up to about $200{ }^{\circ} \mathrm{C}$ they had shown an increasing trend in the compressive strength.

\section{Conclusion}

By critically observing the failure mode of all samples, it can be concluded that geopolymer cement has a considerable amount of strain energy (modulus of toughness), which is evident with the observed stress of $78.14 \mathrm{kPa}$ for $17 \mathrm{ppg}$ sample and class $\mathrm{G}$ of $33.55 \mathrm{kPa}$ at $90^{\circ} \mathrm{C}$. It means geopolymer cementing tends to resist crushing in case overpressure develops around the well tubing due to temperature increment and can enhance the integrity of the system.

Open Access This article is distributed under the terms of the Creative Commons Attribution 4.0 International License (http://creativeco mmons.org/licenses/by/4.0/), which permits unrestricted use, distribution, and reproduction in any medium, provided you give appropriate credit to the original author(s) and the source, provide a link to the Creative Commons license, and indicate if changes were made.

\section{References}

Bakharev T (2005) Resistance of geopolymer materials to acid attack. Cem Concr Res. https://doi.org/10.1016/j.cemconres.2004.06.005 Dusseault M, Gray M, Nawrocki P (2007) Why oilwells leak: cement behavior and long-term consequences. In: International oil and gas conference and exhibition in China, Society of Petroleum Engineers

Falode OA, Salam KK, Arinkoola AO, Ajagbe BM (2013) Prediction of compressive strength of oil field class $\mathrm{G}$ cement slurry using factorial design. J Pet Explor Prod Technol. https://doi. org/10.1007/s13202-013-0071-0

Giasuddin HM, Sanjayan JG, Ranjith PG (2013) Stress versus strain behavior of geopolymer cement under triaxial stress conditions in saline and normal water. Development 7:521-524

Kong DLY, Sanjayan JG (2010) Effect of elevated temperatures on geopolymer paste, mortar and concrete. Cem Concr Res. https:// doi.org/10.1016/j.cemconres.2009.10.017

Kovalchuk G, Fernández-Jiménez A, Palomo A (2007) Alkali-activated fly ash: effect of thermal curing conditions on mechanical and microstructural development-part II. Fuel. https://doi. org/10.1016/j.fuel.2006.07.010

Liu F, Darjani S, Akhmetkhanova N et al (2017) Mixture effect on the dilatation rheology of Asphaltenes-Laden interfaces. Langmuir 33:1927-1942. https://doi.org/10.1021/acs.langmuir.6b03958

Mozaffari S, Tchoukov P, Atias J et al (2015) Effect of Asphaltene aggregation on rheological properties of diluted athabasca bitumen. Energy Fuels 29:5595-5599. https://doi.org/10.1021/acs. energyfuels.5b00918

Mozaffari S, Tchoukov P, Mozaffari A et al (2017) Capillary driven flow in nanochannels-application to heavy oil rheology studies. Colloids Surf A Physicochem Eng Asp 513:178-187

Mozaffari S, Li W, Thompson C et al (2018) Ligand-mediated nucleation and growth of palladium metal nanoparticles. J Vis Exp 1:1. https://doi.org/10.3791/57667

Nasvi MCM, Ranjith PG, Sanjayan J (2012) Comparison of mechanical behaviors of geopolymer and class $\mathrm{G}$ cement as well cement at different curing temperatures for geological sequestration of carbon dioxide. In: 6th US rock mechanics/geomechanics symposium, American Rock Mechanics Association

Shi C, Jiménez AF, Palomo A (2011) New cements for the 21st century: the pursuit of an alternative to Portland cement. Cem Concr Res 41:750-763

Publisher's Note Springer Nature remains neutral with regard to jurisdictional claims in published maps and institutional affiliations. 